\title{
Benin EFL Teachers' Beliefs on the Acceptance of Students with Stigma in their Classroom: Case Studies of "Hounyos" and "Woli"
}

\author{
Arlette J. Viviane Hounhanou
}

\begin{abstract}
Today the concept of inclusion makes all educators responsible for creating supportive learning environment. In Benin schools, consensus is made to accept students with stigma. This article is to explore Benin EFL teachers 'and students' belief on the acceptance of two main categories of students with stigma (Woli and Hounyos). They are concerned with girls who are not allowed to be dressed on top and who keep scarification on their face and chest (Hounyos). The second category are members of celestial church, who keep their hair natural all their life without combing or brushing it (dreadlocks). They are known to be gifted and can predict future. Three public schools and one private school took part in this study. Questionnaire, interview, and classroom observation were used as an instrument in this research. Overall, nineteen students with stigma participated. The results from this research have shown that Benin EFL teachers adopt different approaches on the integration of those specific cases of students in the classroom. Suggestions are then formulated on how Benin EFL teachers should manage the concerned students.
\end{abstract}

Keywords - "Hounyos", Students with Stigma, Teachers, "Woli".

\section{INTRODUCTION}

Over the last 30 years there have been major international efforts to encourage inclusive educational developments. Inclusive education in many countries differs widely. In many developed countries, young people abandon school. Others are placed in a special program, while in others such as poorer countries, children are not able to attend classes due to a couple of reasons. Salamanca Statement [1].

As [2] has concluded: 'There appears, however, to be deep uncertainty about how to create inclusive environments within schools and about how to teach inclusively'. In Benin, a west Africa country, segregated education is in rise and more and more learners/students are far from being place into a mainstream classroom. Faced with these challenges, there is a need to increase interest in the concept of making education more inclusive and equitable for all. In fact, Inclusive education, as originally defined by the Salamanca Statement [1], refers to schooling in which all children, including children with severe disabilities, have access to regular classrooms with the help of adequate support.

There are benefits while dealing with the term inclusion. Several research exit in inclusion but any of them show negative effects. The benefits of inclusion are concerned with better appreciation and understanding of individual differences and being prepared for adult life in a diverse society. In a well-designed inclusive classroom, students meet higher expectations both from their peers and their teachers. They may also see positive academic roles models in their classmates.

In fact, "Woli and Hounyos" students are stigmatized in the classroom by their peers, and by the whole community. Woli are female idol worshipper while Hounyos are the white garment church prophets. Hounyos are adepts of vodoun, and they consult Fâ while Woli come from Celestial Church, which is a personality cult founded by an out of work carpenter in Benin (Africa) named Samuel Joseph Bilewu Oschoffa, who claimed that during a solar eclipse, while lost alone in the wilderness, he called out to The Lord in prayer and humble supplication (he was raised Methodist and knew from his Bible.

[3] in his research on Vodoun and Fâ, has found that in Benin, Vodoun and Fâ are predominantly associated with two ethnic groups, the Fon and the Yoruba. Fâ divination is intrinsically connected to the environment, using materials such as kola and palm oil, leaves, and flour, plus animal sacrifice. Fâ (also known as Ifâ) represents the soul of people' culture. Fâ is the means of communication with the gods and ancestors, speaking to them through a unique and complex system of 256 symbols, each symbolizing 16 parables and 16 local expressions. The consultation process is complicated. Fâ divination usually involves a divining chain. The diviner throws the chains to the ground, where they turn up in one of the 256 possible formations. Each of these corresponds with a sign, which has a specific name. The sign is determined by the diviner and named aloud.

This study attempts to analyze how they are treated and the possible solutions for their acceptance and their inclusion in schools. The main purpose of this paper was to promote the inclusion and the integration of "Hounyos and Woli" in the classroom. It is also to train EFL teachers so that they don't stigmatize this category of learners.

\section{A. Research Purpose}

The main purpose of this research was to promote the inclusion and the acceptance of "Hounyos and Woli" in the classroom. It is also to train EFL teachers so that they do not stigmatize this category of learners. 


\section{B. Theoretical Framework of the Study}

This study was based on inclusion and diversity. Social diversity is common in many communities in today's globalized world This diversity can be seen in any classroom of learners. Both are important factors to consider in teaching contexts which aim to provide quality and relevant education to all learners. Teachers need to ensure that they design learning experiences that are responsive to learners' individual differences and learning styles. In fact, what is an inclusive school? An inclusive school means that all students are welcomed, regardless of gender, ethnicity, socioeconomic background, or educational need. To learn contribute to and take part in all aspects of school life. It is also concerning all students and marginalized groups, not only those with disabilities [4].

This research study took into account the case of "Hounyos and woli". Originally, this is their native name in the south of Benin. "Hounyos" are concerned with girls who are not allowed to be dressed on top and who keep scarification on their face and chest. The term "Hounyos" means someone who is selected or called by the divinity (vodoun) which stands for the spirit in the Fon and Ewe languages, pronounced [vodù] with a nasal high-tone u. Vodoun is practiced by the Aja, Ewe, and Fon peoples of Benin, Togo, Ghana, and Nigeria. "Hounyos" also hold a facial and body mark which enable people to recognize them easily.

In fact, body marking has been used for centuries in parts of Africa to indicate a person's tribal heritage. Most of the time people want to carry the marks of their ancestors. Scarification is a form of body marking and it is the practice of incising the skin with a sharp instrument such as a knife, glass, stone, or coconut shell, in such a way as to control the shape of the scar tissue on various parts of the body. It has a meaning. The explanation of holding scars emphasizes social, political, and religious roles. Facial and body scarification are used for identification of ethnics' groups, families, and individuals. It is sometimes used to express beauty. Scars were thought to beautify the body. It is also performed on girls to mark stages of life: puberty, marriage, or the idea that girls belong to a special divinity. For example, the "Hounyos", an ethnic group in Benin, believes that scarring children usually on their face will connect them with their ancestors. The children are given new names, their hair is shaved, and they are taken to a convent where an oracle helps them to communicate with previous generations.

Students who are "Woli" can predict future on people. They hold long braids on their head and are not allow to put shoes on. The long braid has a meaning. Some braids are a symbol of strength, wisdom, and are something that reflects their identity. Many of our readers stated the braid has a cultural significance, and many felt a connection to the creator, their ancestors, and the earth.

\section{Research Questions}

Two research questions were established for this study.

1. What views do Benin EFL teachers and students hold about "Hounyos and Woli" students?

2. How EFL teachers are trained professionally to meet the needs of students with stigma?

\section{Limitation of the Study}

This study was exclusively limited to "Hounyos". This is applied to girls (female) only. "Hounons" are allowed to wear cloths. This category is specific for boys (male). Here attention was focused on those who are half dressed. Also, this study examined only relationships and association between variables. Additionally, the present study was limited due to the sample's size of the population selected. A single girl Woli student was concerned for the study. Four secondary schools were involved: Malanhoui, Davié, Anavié, and Koutongbé in the department of Ouémé regions of Benin.

\section{LITERATURE REVIEW}

Little research had been made on the inclusion of students with stigma in Benin EFL classes. Consistent literature was not available on the inclusion of Woli and Hounyos students in Benin. This review is concerned with some related research about students with stigma, the definition of the term inclusion, the beliefs of EFL teachers on the integration and acceptance of these categories of students in class, and finally some factors that may impact students and teachers 'attitude toward inclusion.

\section{A. Learners with Stigma}

Stigma involves negative attitudes against someone based on a distinguishing characteristic such as a mental illness, health condition, or disability. Social stigmas can also be related to other characteristics including gender, sexuality, race, religion as in this particular case of this research study, and culture. [5] originally defined stigma as a mark or attribute that makes the person "from a whole and usual person to a tainted, discounted one". According to [6], Stigmatization is a social phenomenon leading to the marginalization of a specific member or a group of the community. It can lead to discrimination and loss of dignity as a result of prejudices by other members of the society.

In addition, Stigma can be viewed as is a powerful social process of devaluing people or groups based on a real or perceived difference such as, class, race, and behavior. According to [7], Stigma is used by dominant groups to create, legitimize, and perpetuate social inequalities and exclusion. Stigma can also lead to discrimination, which is unfair and unjust treatment of an individual based on that socially identified status. The stigma attached to learners holding long hair "Woli" and "Hounyos" is most of the time a source of great anguish and shame. As a consequence of stigma some families may not send their child to school because of the belief that they are retarded and may not achieve well or favorably with their mates and therefore cannot succeed in life [8].

Examples of religious stigma might include, wearing particular head coverings or other religious dress (such as Jewish Yarmulke (explanation) or a Muslim headscarf) or wearing certain hairstyles or facial hair (such as Rastafarian dreadlocks or Sikh uncut hair and beard).

\section{B. Importance of Inclusion}

Students can feel ostracized that is excluded by the society in an education system or when learning through a curriculum that's not diverse or inclusive. In fact, inclusion refers to 
restructuring educational provision to promote 'belonginga [9], i.e., all pupils in a school see themselves as belonging to a community, including those with significant disabilities. As such, inclusion embraces the concept of diversity as a natural state of being human or in educational terms, of being a learner [10].

An inclusive curriculum helps them see that all walks of life are relevant and important, and that they are in a safe environment where everyone is not only accepted but celebrated. Inclusive Education recognizes the right of all children to feel welcomed into a supportive educational environment in their own community. It refers to the capacity of ordinary local schools to respond to the needs of all learners.

\section{Promoting Inclusion Practices in the Classroom}

The world has initiated to introduce educational practices in accordance with various international and national declarations. Among them the Salamanca Statement and Framework for Action [1], and the Dakar Framework for Education for All (2000). Moreover, in 1990, the World Conference on Education for All was held in Jomtien, Thailand. Another conference in (2000) in Senegal gave rise to the Dakar framework for Education for All, in which the international community promises to ensure education as a right for all people, The UNESCO International Conference in Education was held in Geneva in 2008 and the focal point of this conference was the inclusion of a more diverse range of learners, in spite of capacity or personality, as well as the encouragement of respect for the needs and abilities of learners and deduction of all forms of inequity [11].

In fact, the greater part of the world's populations of children with disabilities lives in developing countries; out of a world population just about 150 million live in Africa, Asia, Latin America, the Caribbean and the Middle East [12].

In Africa, with particular reference to South Africa, according to [13] the country is in support of learners in needs according to Section 10 of the Constitution. Furthermore, promotion of Equality and Prevention of Unfair Discrimination Act 4 of (2000), is a core piece of enabling legislation aimed at facilitating the realization of the rights of all people in South Africa, particularly minority groups which have been historically marginalized in the classroom.

In addition, there is a lack of research in the domain of Inclusive Education (IE) in Uganda. The 10 commitments in summary are that the Government of Botswana through the inclusive education policy commits to ensuring that all learners including those who have never been to school before, those who dropped out and those with special needs and /or risk of failure, will be encouraged and supported to get back to school and access education. The government further commits that the vocational training mechanisms will be made relevant and responsive to the children's needs and that teachers' skills will also be strengthened for effective teaching of diverse learners. Finally, access to schools will be strengthened through resource intensification that will make school environments user-friendly (e.g., via providing access ramps and paving school grounds) to all learners.

\section{Attitudes of EFL Teachers towards Inclusion}

[14] investigated a cross-cultural study of teachers' attitudes towards inclusion in a number of countries such as the USA, Germany, Israel, Ghana, Taiwan and the Philippines. The results generated that there were differences in attitude to inclusion between these countries. Teachers in the USA and Germany had the most positive attitudes. Positive attitudes in the USA were attributed to inclusion being widely practiced there as the result of Public Law 94142 .

Other studies have indicated that school district staff who are more distant from students, such as administrators and advisers, express more positive attitudes to inclusion than those closer to the classroom context, the class teachers. Headteachers have been found to hold the most positive attitudes to inclusion.

Other studies by [8] also examined mainstream and special teachers' perceptions of inclusion through the use of focus group interviews. The majority of these teachers who were not currently participating in inclusive programmes had strong, negative feelings about inclusion and felt that decision makers were out of touch with classroom realities. The teachers identified several factors that would affect the success of inclusion, including class size, inadequate resources, the extent to which all students would benefit from inclusion and lack of adequate teacher preparation.

However, the results were significantly less positive in Ghana, the Philippines, Israel, and Taiwan. The authors reasoned that this could probably be due to limited or nonexistent training for teachers to acquire integration competencies; the limited opportunities for inclusion in some of these countries; and the overall small percentage of children who receive services at all (none of these countries had a history of offering children with SEN specially designed educational opportunities).

Currently, there are a number of learners with special educational needs in the regular schools (Government of Botswana, 2017). The success of this initiative depends on a number of factors; one of which is the teachers' knowledge and pedagogical skills in teaching learners with special educational needs and exposure to positive practices of inclusion. The way student teachers experience knowledge and skill acquisition at the University lecture rooms and also during teaching practice is an essential part of understanding the potential success of providing effective teaching to learners with special educational needs.

\section{E. Factors Impacting Students and Teachers' Attitude toward Inclusion}

\section{1) Labeling}

Labeling refers to the process of identifying that a student meets eligibility criteria for special education services. It is also a process of creating descriptors to identify persons who differ from the norm. A label or tag is given to anyone who is dif can lead to bullying and marginalization in schools. Children change and develop but labels, unfortunately, tend to stick. This can ultimately become difficult for such learners to leave behind negative reputations. For example, in Benin, girls who are half dress on top are labeled as "Vodounssi or Hounyos" and students with long and uncombed hair are labeled "Woli" meaning somebody who has vision and can predict future. Assigning labels to students in education systems usually brings about negative effects including 
stigmatization, peer rejection, lower self-esteem, lower expectations, and limited opportunities.

\section{2) Attitude}

An attitude is an expression of a favorable or unfavorable evaluation of a person, place, thing, or event. It is also the belief that one has towards people and surroundings. Regarding education, students' or teachers' positive attitude may influence their academic performance. [15] defined the word as a psychological tendency to view a particular object or behavior with a degree of favor or disfavor. According to [16] in her research of teenagers with Albinism for example, he notes that one of the results of negative attitudes learners with albinism experience in schools is name-calling. In addition, the negative attitude experienced by learners with albinism is that of being treated unfairly due to their skin color and they are called names that demean and humiliate them in school. According to [17], the attitudes of teachers, school administrators and peers affect the inclusion of children with disabilities or who are labeled. Some schoolteachers, including head teachers, believe that they are not obliged to teach children with disabilities or labeled students because they were not trained in special education.

\section{3) Discrimination}

Discrimination is showing of favor, prejudice, or bias for or against a person on any arbitrary grounds, for example on the basis of sex, color, culture, and language [15]. Discrimination can be on the basis of ethnicity, nationality,

age, gender, race, economic, disability and religion.

Discrimination against "Woli and Hounyos" is based on myths and misconceptions about the origin and the culture of those specific students.

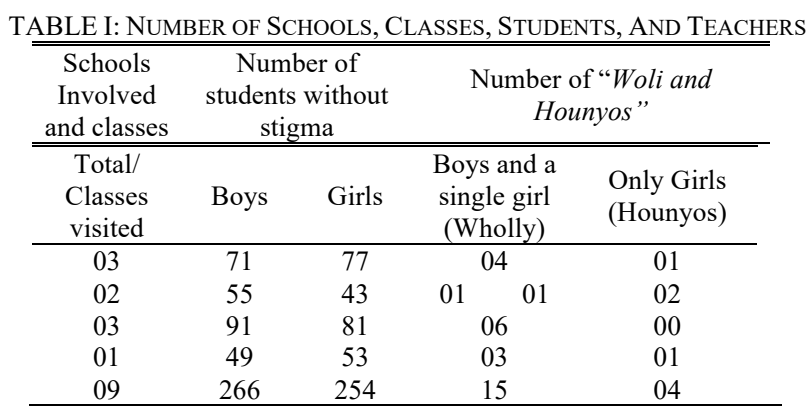

\section{RESEARCH PROCEDURE}

The survey was carried out in four main public secondaries. The study involved 520 regular students and 19 students in needs. 09 classes were visited. The selection was made on the basis of the presence of students with exceptionalities in each school. The researcher checked and controlled the effectiveness of students' presence prior to data collection. Questionnaire, interview, and classroom observation were used as an instrument in this research. Permission was granted from the Vice-Principal of each secondary school prior to school visit.

\section{A. Instruments}

Three main instruments were used in order to conduct the study. The first instrument was the questionnaire It consisted of reported situational variables. A Likert scale measuring beliefs relative to inclusion was used and composed of 11 items taken from the opinions relative to mainstreaming (ORM) scale [18] which were adapted by the researcher in Benin context. The questionnaire used consisted of 11 items. The second instrument was the interview and the third one was the class observation. Those instruments were used to judge the level of teachers and students' beliefs on the acceptance of students with Special Needs in their Classroom. Observation was conducted in classroom setting in 09 classes.

Attention was focused on students 'interaction in class, and in the way EFL teachers manage Woli and Hounyos. Each observation lasts 55 minutes in the classroom.

\section{B. Findings and Data Analysis}

Data were presented and analyzed; each question was interpreted according to students' responses on the different statements. The objective was to measure students' beliefs relative to inclusion, and integration of "Woli and Hounyos" students. Interview responses from EFL teachers were carefully analyzed, summarized, and reported. The account of class observation was also summarized.

\section{Questionnaire Responses}

The statistical results from question 1 and 2 have shown that 439 students, that is $84.42 \%$ agree that they felt comfortable in working in group with a Woli student. 81 students disagree, that is 15.57 on the statement. The findings for the second question indicated a slight similarity between responses for question 1 and 2. The different reasons provided for the choices were common to all the learners who disagree. For them, Woli students dream a lot in class. Generally, they are absent minded. From time to time, they are tormented by bad spirits, and use interpretation and threat for any problem that may occur in classroom situation.

For question 3, 449 students over 520, that is $86.34 \%$ agree that they ask questions related to "Woli and Hounyo" sources. Woli are originated from celestial church and Hounyos came from vodoun. 71 students, that is $13.65 \%$ confessed they do not ask them questions about their source. For question 4, they recognized the sincerity of those special students since people confirmed the same source.

For question 5, 361 students that is $69.42 \%$ agree they have consulted a Woli in their classroom once in their life. 159 students, that is $30.57 \%$ disagree they have never consult a Woli student in their classroom.

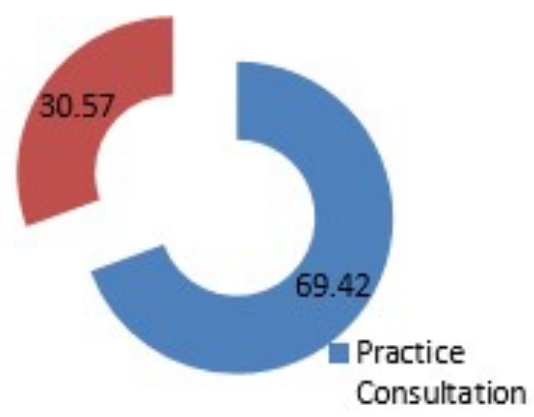

Fig. 1. "Woli" student's Consultation.

The reasons of the consultation differ from one student to the other. The majority of students $(n=277)$ consult to know more about the important chapters to be revised for the tests. 
Another group of students $(n=56)$ consult to learn more about their future, lucky, get a very nice girlfriend in the classroom, and whether they will become rich or not. A third group of students $(n=28)$ consult to defeat evil.

Satisfaction after the consultation also differs from a group of students to the other. Thus 130 students, that is $25 \%$ claimed they were satisfied with Woli's consultation. 164 students confessed they were sometimes satisfied with the consultation, that is $31.53 \%$, and 221 students, that is $43.6 \%$ disagreed with the satisfaction. Below is the illustration of the degree of satisfaction of the Woli's consultation.

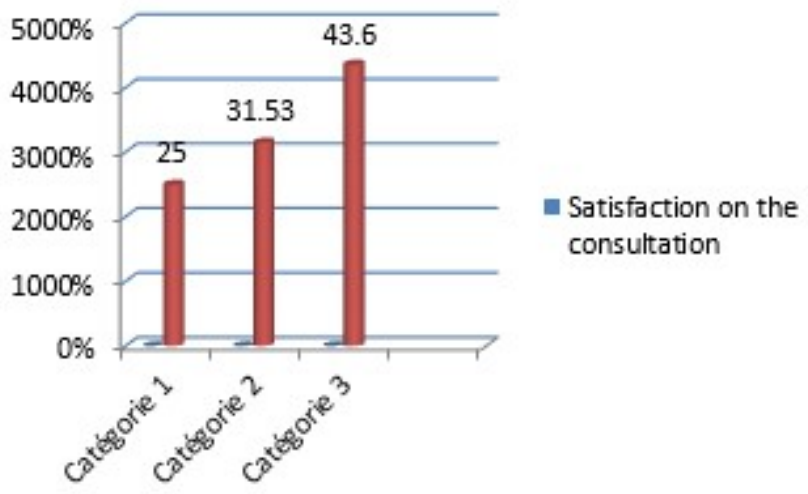

Fig. 2. Degree of satisfaction of the consultation.

The consultation is not free. $98 \%$ claimed that they pay money in exchange. $2 \%$ declared they do not pay. The reason may depend. For question 8 , the majority of students $(n=497)$, that is $95.57 \%$ confessed that consultation took place at the school field. 24 students, that is $04.61 \%$ declared to have consultation in the classroom. These findings may be interpreted as a means for students to secure themselves. It may also be probable that the consultation took place in the absence of the teacher or at the end of a lesson. Classrooms were generally far from the school administration office. Also, the setting in the school field was not appropriate because of the space available for such a practice. Students may pretend to play and do something else. But none of the students agreed on the statement that consultation occurred out of school.

The data collected for question 9 were similar to those of the previous question. The majority of students $(n=489)$, that is $94.03 \%$ have their consultation after classes, and 31 students, that is $05.96 \%$ accepted to have consultation before classes. This implies that students may come earlier before 08 o'clock. They may also lie to their parents at home that they have classes at 7o'clock. In the majority of cases there were ceremonies to perform after the consultation. Students $(n=$ 244), that is $46.92 \%$ confessed that they do have such practices whereas 276 students, that is $53.07 \%$ disagree not to be instructed to perform rituals. After consultation, the "Woli" student instructed his "customers" to practice what he/she recommended. Generally, he/she provided a black soap to use for bathroom. In addition, he/she demanded coconuts students going to break to defeat evil. Other should fast at least for 7 days. Another category of students should go to the sea to have a bath so that they cure themselves and leave their sin before coming at home. After consultation, there were never discussions at home with parents. Students never shared information with parents that they were under medication or prescription.

\section{Interview}

The researcher interviewed 07 teachers. All interviews were recorded. Recorded interviews were transcribed and then translated into English. Data collected through interviews were analyzed using the content analysis techniques. After transcribing the interviews, the researcher after several readings was able to make some sense of the data and constructed a system that allowed all of the data to be categorized systematically. The interviews' sessions lasted from 15-25 minutes depending on the way the participants are explaining the phenomenon. Participants shared their experiences. Each interview was face-to-face interview with the participating teachers. These interviews were recorded by researchers with teachers 'permission. It took approximately ten days to complete interviews from all 07 teachers.

\section{E. Interview Responses}

1. How do you deal with the presence of "Woli" in your classes?

-The management of Woli is sensible. They are object of distraction due to the fact that they are different. They hold long braid, they never put shoes. Their mates are curious to learn more about them.

2. How do you deal with the presence of "Hounyos" in your classes?

It is not common to have girls who are half dressed in Benin classrooms. Having them remind me that I have a double responsibility regarding their interaction and socialization among the other normal students.

3. Do the presence of "Woli and Hounyos" impacts the classroom activity?

The majority of teachers confessed that they handle problems when they occur. But a teacher turned that he experienced a case where the Woli student was really frustrated by the attitude of the administrator. The superintendent visited his class to control students who do not follow the regulation that this having their hair cut.

At first sight the superintendent did not realize to have a Woli student. He thought he was a regular student and asked him to go out. A student whispered: "Good job dear supervisor! I am happy for the wholly student. He needs to be dismissed too. Why should teachers allow him and not the other? After the control, I draw the superintendent 'attention on the fact that the wholly was a special student. He was accepted but the atmosphere was tense, and this attitude impacts the progress of the instruction he gave.

4. Have you ever seen the manifestation of vodoun regarding "Hounyos" in the classroom?

It is not common that Hounyos go into a trance in class, but it may happen after school day or during extracurricular activities such as working in group to clean the school yard or during a concert organized by the school. Here are the words of a female teacher: "I was terrified by the strength of the student who went into a trance. The fellow classmates ran away, and I thought she is going to die because of her breath and the switching position of her eyes" I was really confused, and I called on the administration for help.

A male teacher turned that he was surprised by a Hounyo 
'attitude when she started uttering words in unknown language. The words did not make sense. She went out, kept pronouncing the same words, again and again.

Students were laughing. Finally, the Vice-Principal called her parents. Another female teacher confessed that "she experienced a case where a Hounyo student was crying, singing aloud, and performing vodoun danse in class".

5 . What do you think about their performance?

Most of the time Woli and Hounyos do not achieve well in class. Hounyos specifically are more likely to achieve well. But sometimes Woli students abuse and take advantage of their status to miss classes and to quit evaluation. A wholly student told me: "I can no longer stay in this classroom because I have a wrong vision. I predict that a bad event for the class". But there was no bad event. Also, the regular students confessed that they paid money to Woli students so that they predict chapters needed to be revised for tests. The money ranged from 100 hundred CFA to 1200 CFA out of class, if possible, for additional ritual. This may depend on each situation. Sometimes they have magic to help their friend to obtain agreement from girls. When they have health problems there is an interpretation which make them stay in church or in convent for healing. There is no alternative for hospital.

6. What are the relationships of these special students with their mates?

The interaction is good. When it comes to work in pairs or collectively, they feel comfortable. Some students use their names directly. "Hounyos/Woli". There is no complex, they easily accept themselves. They play together during the break time.

7. Is there any warning from the administration before you have those special students in your class?

$100 \%$ of teachers interviewed have confessed they did not receive a warning on the presence of "Woli and Hounyos" in their classroom. "Personally, I realized that I have two Woli in my class. I've never received some advice from the vice principal or the principal on the way I should treat those students. I know they are different, and I pay attention to the choice of my words while dealing with some topics such as religious views"

8. Do you think we should accept "Wholly and Hounyos" in the classroom?

Out of 07 teachers, four (04) teachers were not sharing the point of view that we should accept Hounyos and Wholly in the classroom. They were against their inclusion due to their behaviour in the classroom. They are stigmatized and are constantly object of distraction. It is better to create a specific environment for them. Three (03) teachers believe that we should keep them with other students and explain their origin and status so that everybody is informed about their way of behaving.

\section{F. Classroom Observation}

To obtain reliable data, teachers were not informed on the objective of the class visit. Arrangement was made with the principal to check on the presence of "Woli and Hounyos" in the classroom selected to be observed. The researcher informed the teachers that she was going to work on learners and their interaction. The researcher has paid attention to the sitting arrangement of students and their interaction.
Attention was also focused on Students' mark book to check on their achievement. Classroom was observed prior to interview.

From the classroom observation, the researcher noticed that only a minority of teachers managed quite well the interaction and their involvement with the other students whereas the majority did not. On the nineteen selected students in need, only six (06) were well integrated and well treated by teachers, that is $31.57 \%$. The remaining (13) students, that is $68.42 \%$ were stigmatized and not welcomed in the classroom. For example, among the classes observed there was a teacher who had asked a "Woli" student to continue the reading of the text and he called him with his nickname "Hey! The "Woli" in the back! are you with us or you're dreaming?" This makes everybody laugh but the boy disliked such a behavior, and it was not a fun for him. The teacher was expecting the researcher to laugh but it did not happen. So young teachers have the view that schools should exclude them from schools and create a special program for them. The researcher had noticed that some students had health problems, and this was linked to the fact that they went on a fast for hours and even for days. They were instructed to eat fruits only. Ultimately, they became weak and went into health crisis.

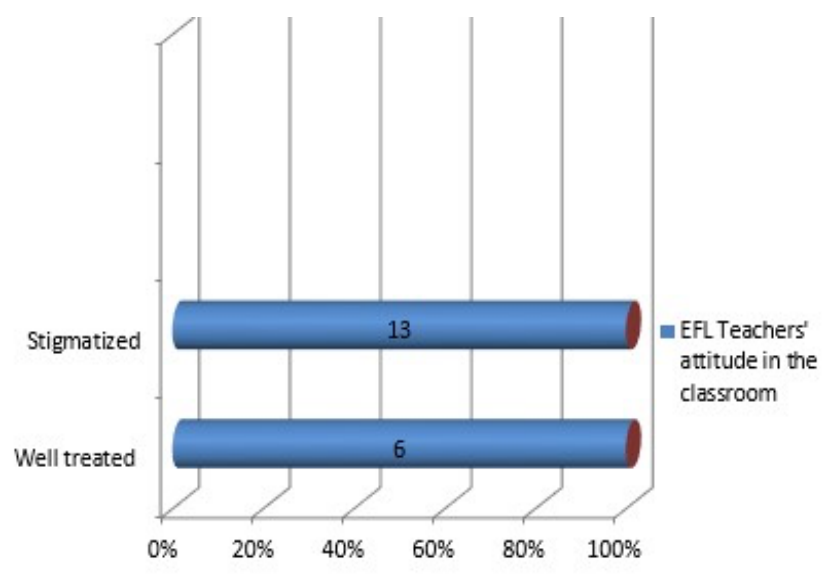

Fig. 3: EFL Teachers' attitude in the classroom.

\section{Discussion}

The access in inclusive education has received less attention in Benin. However, to make it possible stakeholders have to have to further develop teachers' competencies in this particular form of education. It is then crucial to provide adequate documentation on the matter. All these will require collaborative efforts from educationalists programs.

\section{A. Beliefs of Teachers and Students}

EFL teachers and students' beliefs differ from one category to the other one. It is obvious that "Woli and Hounyos" are more and more involved in schools today in Benin. In the past parents never send them to school. It is also obvious that they were subjected to name calling. They were frequently bullied, beaten by their fellow students and treated as a misfit or outcast. Some of them were avoided by their peers who refused to sit, eat or play with them/ or interact. Others were always humiliated by their mates when they appeared in the classroom. Not all people do rely on their culture. The marginalization of such students is not visible today. This 
attitude has an impact on "Woli and Hounyos" performance. The findings in classroom observation and in the mark, book have shown that "Hounyos" students achieved well than "Woli".

The percentages from the questionnaire, interview and classroom observation provides a deeper understanding of students and teachers' beliefs towards inclusion of "Woli" and "Hounyos" in Benin classroom context. The findings from the interview revealed that only a minority of EFL teachers accept the inclusion of those special students.

Furthermore, the data collected on the ground have indicated that the presence of "Woli" in the classroom generates another area of interest, that is a business activity. "Woli" students considered consultation and ritual ceremonies more than their academic studies. The findings on the degree of satisfaction have also shown that the service provided was below the satisfaction expected by students. This means that the results from the consultation were not reliable. The regular students who discovered the truth became septic and have started developing doubt. They were fixed on their position and noticed that the consultation was a wrong story and never existed. Consequently some "Woli" students lose their reputation and influence on students.

\section{B. Professional Development}

There was no professional development that meet the needs of EFL practitioners in the domain. Being a teacher in Africa classroom context, especially with students in needs requires a training. Each student is unique and may come from varied background. When the teacher is not well equipped with special students he may be surprised. Then there should be more programs in colleges of education and universities aimed at equipping pre-service teachers the skills needed to teach students in the context of inclusion.

Professionally teachers' attitude varied from experienced to beginners one. Veteran teachers were more likely to handle "Woli and Hounyos". They were well-treated, and their participation was effective. Non experienced teachers tended to minimize their presence and even laugh at "Woli" students. There is a sufficient consistency regarding this attitude because [14] also came to the conclusion that, in general, teachers with 14 years or less teaching experience had a significantly higher positive score in their attitude to inclusion compared with those with more than 14 years. They found no significant differences in attitudes to inclusion among teachers whose teaching experience was between one and four years, and nine years and ten and 14 years (no mention was made based on individual country).

While observing teachers and students' attitudes in class, female teachers tend to lead Wholly and Hounyos students appropriately. They were more flexible han male students. This evidence is in accordance with some previous studies who had noted inconsistency with regard to gender. They found that female teachers had a greater tolerance level for integration and inclusion for special needs persons than did male teachers [19] [20]. [21], for example, found that there was a marginal tendency for female teachers to express more positive attitudes towards the idea of integrating children with behaviour problems than male teachers.

The review has also demonstrated that some teachers have a positive view towards inclusion all over the world if conditions are met. This idea strongly correlated with the findings of [22] when he has explained that there are challenges in both developed and developing countries, such as gaps between policies and practices, discouraging behaviors towards inclusion, and lack of sufficient funding. Inclusive outcome is positive, and teachers felt if all facilities are provided, the results would be more encouraging.

This study only considered the implementation of inclusive education at the secondary school level in Benin. Therefore, it is urgent to have advanced research in getting the impressions about the inclusion of types of students such as the students who are believers of other religious practice.

Academic performance is of great importance in education because it is strongly linked to the positive outcomes' teachers value. For this research, attention was focused on the academic results of the 19 selected students. The researcher noticed that the single Woli girl, and the single Hounyo girl really performed well in class. Their interaction was different while compared to the other special students. They felt comfortable and did not develop any complex with their mates, and in group. Wholly students were not willing to perform well. Their participation was not visible, and their academic results were below the expected one.

\section{IMPLICATIONS}

The findings from this study shed light on some issues regarding Woli and Hounyos students' attitude in the classroom. The results have clearly indicated that teachers in general and particularly EFL teachers should change their beliefs toward the concept of inclusion in the classroom. Secondly, regular students also need a change in their attitude.

The data collected were the indication that parents should be involved in the development of curriculum and sensitize Woli and Hounyos students on a number of attitude and behavior towards the school community.

Apart from parents, the government of Benin should show more commitment to secondary education program with the adequate training for teachers and by sensitizing special students on good attitude in class. This idea was strongly supported by the studies of [23] and [24], who have focused educators' attention on the importance of training in the formation of positive attitudes towards integration. They have studied the attitudes of college teachers in the UK towards students with SEN and their integration into ordinary college courses. Their findings showed that college teachers who had been trained to teach students with learning difficulties expressed more favorable attitudes and emotional reactions to students with SEN and their integration than did those who had no such training.

A pre-condition is also necessary prior to "Woli and Hounyos's acceptance in school. The school setting cannot be transformed to a ritual place where consultation becomes a routine and a business activity for the other regular students.

All stakeholders should establish regulations so that Woli and Hounyos students are well-equipped of their limits. For instance, it will be strictly forbidden for "Woli and Hounyos" students to predict what is going to happen in the future, or to use threat towards their mate. In the same way "Woli and Hounyos" students will be subjected to the same punishment 
as regular students.

\section{CONCLUSION}

This study has discussed the understanding and practices of inclusive education, and the main challenges in developing inclusive education in Benin EFL classes. The research has considered issues in inclusive classrooms in other countries, some practical definitions and terms used in religious context in Benin Republic.

The results indicate that, in Benin a smaller minority of EFL teachers strongly approved inclusion. The findings have also shown that students with exceptionalities need to be taught differently. They need some accommodations to enhance the learning environment. Not everyone learns in the same way. More efforts are needed to be directed towards educational specialists in terms of the quality of training with regard to the content of curriculum for exceptional learners. Students in need should receive additional training on how to develop positive attitude in class. Although no previous research had not been undertaken for the inclusion of Hounyos and Woli in Benin, future research may examine the integration of other exceptional students in classroom such as the case of Mamiwata, Dansi, Hounons, and adeptes of Tronc.

\section{APPENDIX}

Questionnaire for Students (Adapted by the Researcher).

Please indicate the extent to which you agree or disagree on the following statements using the scale below:

1. Do you feel comfortable in working in group with a Woli student?

- Yes

- No

2. Are you afraid sometimes?

- Yes

- No

If yes, state the reasons (threat)

3. Do you ask them questions related to their source/reality?

- Yes

- No

- If yes, what did they tell you?

4. Do you think that they were sincere?

- Yes

- No

5. Have you ever consulted a "Woli" student in your classroom?

- Yes

- No

- If yes, what about?

6. Are you satisfied after the consultation?

- Yes

- No

- Sometimes

7. Is the consultation free?

- Yes

- No

- Sometimes

8. Where the consultation happens?
- Classroom

- School yard

- School field

- Out of school

9. When the consultation happens?

- Break time

- Before classes

- After classes

10. Is/Are there ceremonies to perform after the consultation?

- Yes

- No

- If Yes, what the Woli student ask you to do?

11. Do you tell/ Discuss with your parents about the consultation?

- Yes

- No

Interview Sheet designed for EFL teachers.

1. How do you deal with the presence of Woli in your classes?

2. How do you deal with the presence of Hounyos in your classes?

3. Do the presence of Wholly and Hounyos impacts the classroom activity?

4. Have you ever seen the manifestation of vodoun regarding Hounyos in the classroom?

5. What do you think about their performance?

6. What are the relationships of these special students with their mates?

7. Is there any warning from the administration before you have those special students in your class?

8. Do you think we should accept Woli and Hounyos in the classroom?

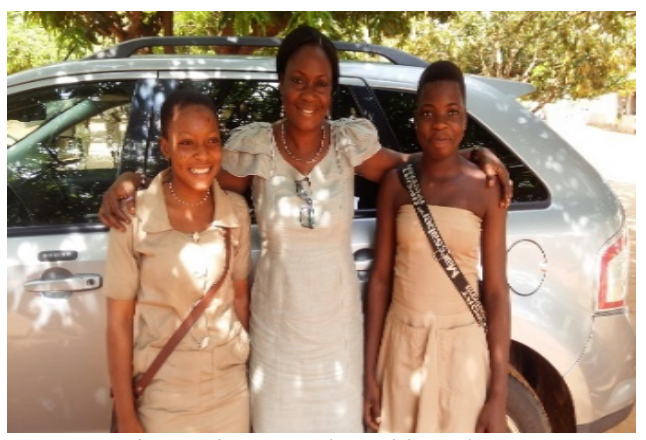

Fig. 1. The researcher with students.

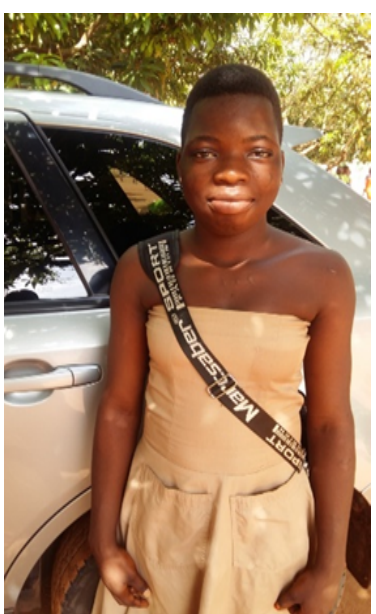

Fig. 2. A Hounyo. 


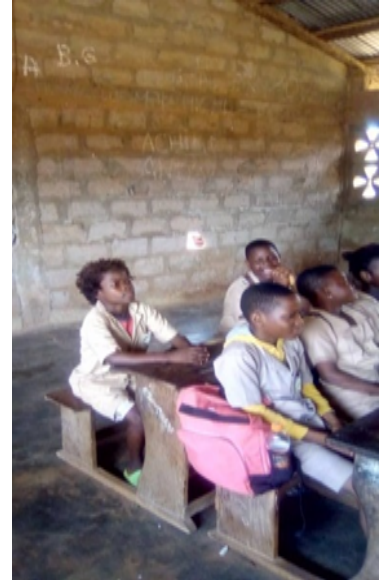

Fig.3. A Woli student.

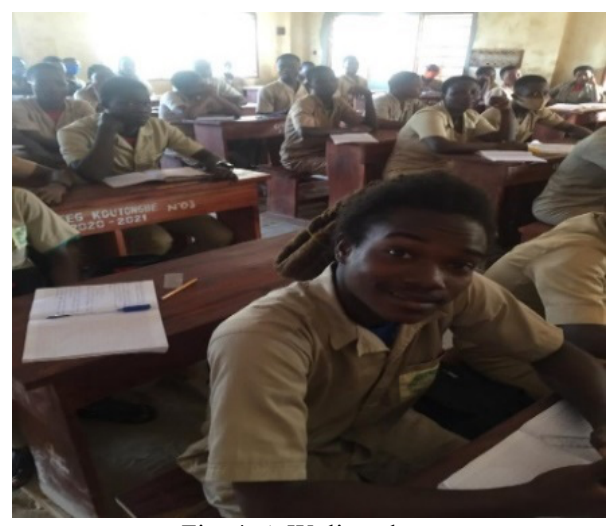

Fig. 4. A Woli student.

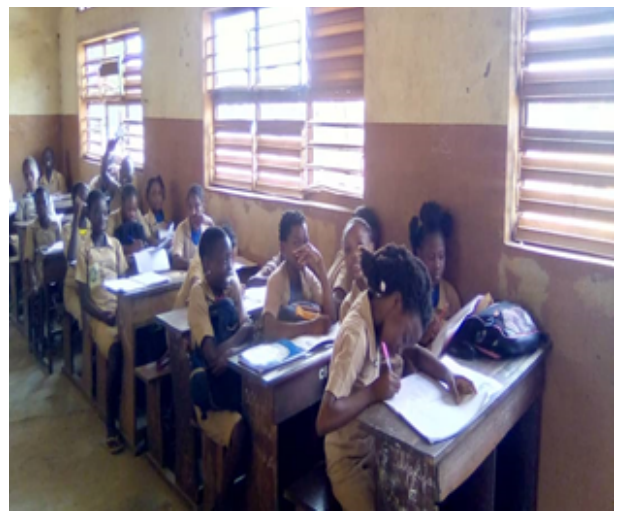

Fig. 5. The single girl (Woli).

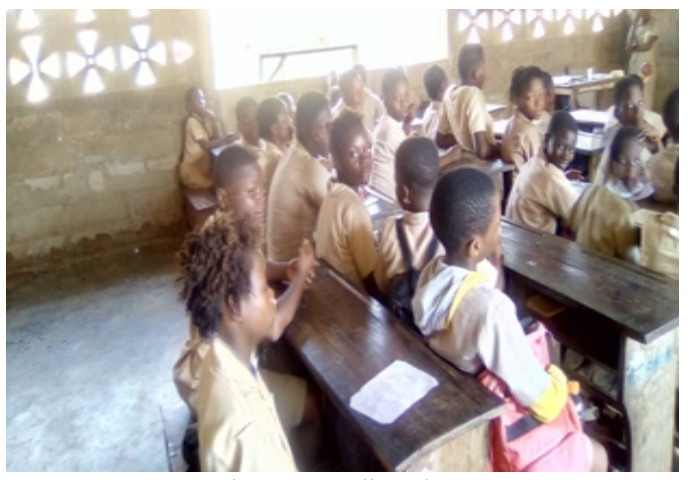

Fig. 6. A Woli student.

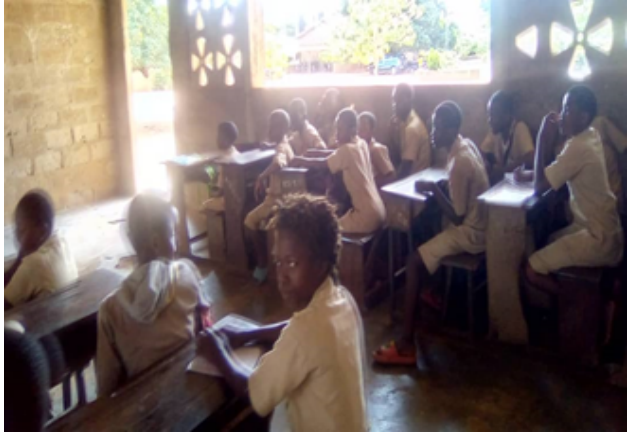

Fig.7. A Woli student.

\section{REFERENCES}

[1] United Nations Educational, Scientific and Cultural Organisation (UNESCO). The Salamanca statement and framework for action on special needs education. Salamanca: World Conference on Special Needs Education: Access and Quality. 1994, June 7-10.

[2] J. Allan, "Rethinking Inclusive Education: The Philosophers of Difference in Practice". Dordrecht: Springer. 2008.

[3] G. O. Médiohouan, (1993). Canadian Journal of African Studies. Vol.27, No.2 (1993), pp.245-258 Published by Taylor \& Francis, Ltd.

[4] G. Thomas, "A Review of Thinking and Research about Inclusive Education Policy, with Suggestions for a New Kind of Inclusive Thinking." British Educational Research Journal 39 (3): 473-490. 2013.

[5] E. Goffman, Stigma: "Notes on the Management of Spoiled Identity". New York; Simon \&Schuster.1963.

[6] P. Corrigan, "An attribution model of public discrimination towards persons with mental illness". J Health Soc behav. 2003; 44(2) :162-79. doi: $10.2307 / 1519806$.

[7] J. Ogden, and L. Nyblade,"Common at its core HIV related Stigma across contexts". Washington, D.C.: International Centre for Research on Woman. 2005.

[8] S. J. S. Vaughn, B. Jallad, J. Slusher, L. Saumell, “Teachers' views of inclusion. Learning Disabilities Practice”, 11, 96-106. 1996.

[9] N. Kunc, The need to belong. Rediscovering Maslow's Hierarchy of Needs. In R. A. Villa, J. S. Thousand, W. Stainback, \& S. Stainback, restructuring for caring and effective education: Administrative guide to creating heterogeneous schools (pp. 25\}40). Baltimore: Paul Brooks, 1992.

[10] P. D. Bayliss, "A curriculum for inclusion." Curriculum, 18(1), 15 \}27. 1997

[11] UNESCO. "Final report- International conference on education", 48th Session. 2009

[12] C. J. Eleweke, \& M. Rodda, The challenge of enhancing inclusive education in developing countries. International Journal of Inclusive Education, 6(2),113-126. 2002.

[13] V. D. Msomi, Experiences of learners with albinism in primary and secondary school in UMLAZI District. Durban: University of Kwazulu Natal. 2014

[14] Y. Leyser, G. Kapperman, and R Keller, Teacher attitudes toward mainstreaming: a cross-cultural study in six nations, European Journal of Special Needs Education, 9, 1-15. 1994.

[15] D. J. Albarracin, (2005). The hard book of attitudes. Routledge, london sotish social attitudes survey data archive: http//www.esds.ac.uk/government/ssa/.accessed on 22/09/ 18 .

[16] D. M. Selepe, (2007). Teenagers with oculocutaneous albinism in polokwane: their self-esteem and perception of societal attitudes master's thesis, University of Limpompo. Limpompo: retrieved from:hdl.handle.net/103886/97. Accessed on 14/09/18

[17] S. Kasonde-Ngandu, \& S. Moberg, Moving Towards Inclusive Education. A Baseline Study on the Special Educational Needs in North-Western and Western Provinces of Zambia. Basic Education Sub-Sector Investment Programme BESSIP, 2001.

[18] B. Larrivee, Psychometric Analysis and Revision of Opinions Relative to mainstream scale. Exceptional Children, 62(2), 132-149,1995.

[19] D. Aksamit, M. Morris, and J. Leunberger, (1987). Preparation of student services, professionals and faculty for serving learning disabled college students. Journal of College Student Personnel, 28,53-59.

[20] J. Eichinger, J. Rizzo, and B. Sirotnik, Changing attitudes toward people with disabilities. Teacher Education and Special Education, 14,121-126. 1991.

[21] D. Harvey, The Urbanization or Capital, Oxford: Basil Backwel, p. 165-84. 1985. 
[22] J. Charema, (2007). From Special School to Inclusive Education: The Way Forward for Developing Countries South of the Sahara. The Journal of the International Association of Special Education; 8(1).

[23] A. Beh-Pajooh, (1992). The effect of social contact on college teachers' attitudes towards students with severe mental handicaps and their educational integration', European Journal of Special Needs Education, 7,231-236.

[24] P. Shimman, (1990). The impact of special needs students at a further education college: a report on a questionnaire', Journal of Further and Higher Education, 14,83-91.

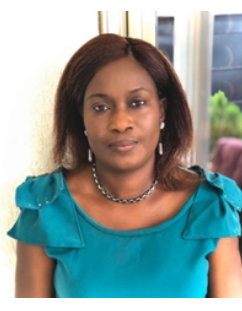

Arlette Hounhanou is born in 1970 at Porto-Novo (Benin), a West Africa Country. She is previously an English instructor at Benin secondary school and now a Senior lecturer of English Didactics at Benin University.

She holds a Master degree at Florida University in 2003 and obtains her doctorate at the University of Abomey-Calavi (Benin) in 2013. She attended several national and international meeting in education. Her areas of research are on Educational

Leadership, Evaluation, Learning styles and strategies, Transformative Education, Instructional Materials, and Inclusion. She is member of Benin English Association. She has published several articles among which:

1. "The Competency-Based Approach: The Concept of Group in Benin EFL Teaching". Studies in English Language Teaching Journal, Los Angeles, Scholink, 2017.

2. "Examining the Way Benin EFL Part-time Teachers Conduct their Teaching, Learning and Evaluation Processes. Journal of Applied Linguistics and Language Research. USA, 2018.

3. "Pedagogical Advisors and EFL Teachers' Scaffolding in PostObservation Feedback Conferences in Benin". Les Annales de la FLASH, UAC. (Benin) 2019.

She is now working on how to contextualize teaching and design local materials in EFL classes. She is currently the head of English Department at the Faculty of Human and Social Science (FASHS) at Adjarra Campus/University of Abomey-Calavi. (Benin). 